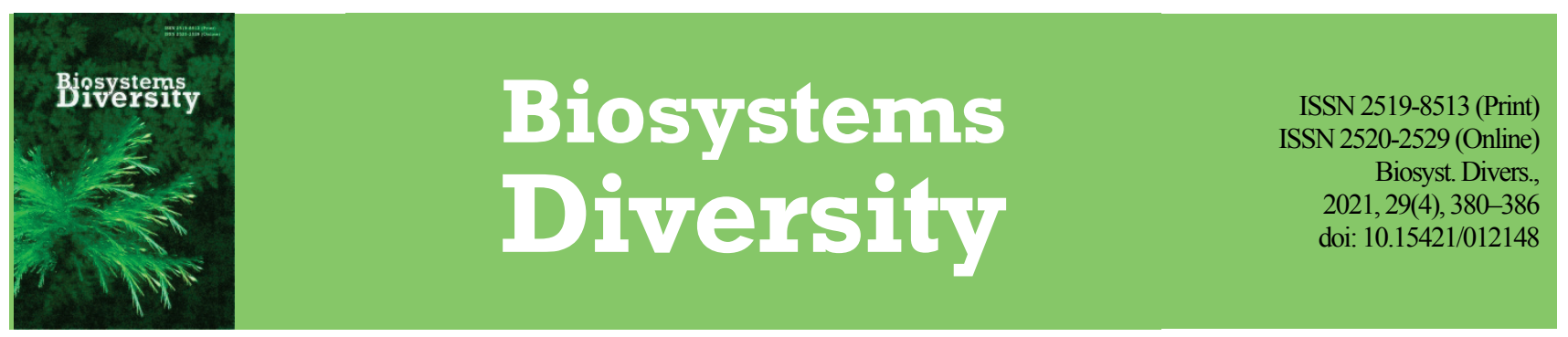

\title{
Meander reshaping - the formation process of a wintering riverbed depression of fish
}

\author{
A. A. Chemagin \\ Tobolsk Complex Scientific Station of the Ural Branch of the Russian Academy of Sciences, Tobolsk, Russia
}

Article info

Received 14.10.2021

Received in revised form 09.11 .2021

Accepted 10.11.2021

\author{
Chemagin, A. A. (2021). Meander reshaping - the formation process of a wintering riverbed depression of fish. Biosystems Diversity, \\ 29(4), 380-386. doi:10.15421/012148
}

Tobolsk Complex Scientific Station of the Ural Branch of the Russian Academy of Sciences, Osipov st., 15 , Tobolsk, 626152, Russia Tel.: + 7-345-622-09-33. E-mail:

chemaginaa@yandex.ru

The study of the spatiotemporal distribution of fish is an important and poorly studied aspect of the ecology of aquatic organisms. The research work was performed using the modem hydroacoustic method and geographic information systems. A section in the lower reaches of the Irtysh, a large transboundary Siberian river (in Western Siberia, Russian Federation), was studied. It has a strong development of meandering. The merging (i.e., reshaping of closely spaced meanders and erosion-accumulating channel processes) results in development of wintering riverbed depression, which is a critical "temporal bottleneck" during the winter period of the fish life cycle. The average density of fish in the study area in summer and autumn was 8,031 and 9,194 individuals per ha, respectively. Analysis of the distribution of fish showed that the distribution in the horizontal aspect had a more aggregated character in the autumn. In the vertical aspect, it had a more surface (pelagic) character. The ichthyofauna in the water area of the riverbed depression is mainly represented by cyprinids. The loop-shaped evolution of the channel formed a section of the river with multidirectional, circulating, and counter-current flows. It also created zones with depths exceeding $20 \mathrm{~m}$ and aggregations of fish. These features characterize the studied water area as a wintering riverbed depression of the fish of the Lower Irtysh. This section of the river should be included in the list of protected wintering biotopes of fish in the West Siberian fishery basin, which will ensure the conservation of fish at the critical stage of the life cycle.

Keywords: wintering of fish; meander reshaping; channel processes; aggregations of fish; winter mortality of fish.

\section{Introduction}

The Irtysh River is an important component of the Ob-Irtysh Basin and the largest tributary of the Ob River (Ecology of fish of the Ob-Irtysh Basin, 2006). In the lower reaches of the Irtysh River, there are wintering riverbed depressions with significant depths $(>35 \mathrm{~m})$, which form on the meanders of the watercourse (Borisenko et al., 2013; Mochek et al., 2019). For fish, wintering is one of the critically important stages of their life cycle (Thayer et al., 2017; Wang et al., 2019; Studd et al., 2021; Sutton et al., 2021); in winter, juvenile fish have increased mortality compared to fish of older age groups (Deslauriers et al., 2018; Fernandes \& McMeans, 2019; Takegaki \& Takeshita, 2020). During this season, many species of fish (including sturgeons) prefer "temporal bottleneck" - wintering riverbed depressions (Thayer et al., 2017; Andrews et al., 2020). In the water areas of the riverbed depression, the fish population is aggregated (including because of the limited movements in winter). This means that the formation of aggregations is determined by the behaviour of fish and the characteristics of habitats (Gerasimov et al., 2019; Mochek et al., 2019). Aggregation in the "hydrodynamic shadow" of the riverbed depression is part of the fish survival strategy, because it allows them to reduce the waste of accumulated lipids (Thayer et al., 2017; Takegaki \& Takeshita, 2020), since it has been shown (Secor \& Carey, 2016; Thayer et al., 2017; Takegaki \& Takeshita, 2020) that the body's ability to survive during prolonged fasting is based on behavioural patterns and mechanisms that reduce metabolism.

Cyprinids predominate among fish populations of the riverbed depression, but there are also aggregations of sturgeons and coregonids (Borisenko et al., 2013; Mochek et al., 2019). Riverbed depressions are protected by the Federal Agency for Fisheries of the Russian Federation: the only allowed type of fishing in these areas is research fishing. The conditions of the channel of the Irtysh River vary. As a result of the erosion-channel processes, one can observe its reshaping and change in bathymetric characteristics (horizontal and vertical deformations of the channel) (Ecology of fish of the Ob-Irtysh basin, 2006). Recently, many studies of meandering sections of rivers have been performed (Blanckaert
\& de Vriend, 2010; Ottevanger et al., 2013; Tang \& Knight, 2015; Akhtari \& Seyedashraf, 2017; Chavarrías et al., 2019), but the mechanism of erosion and sediment processes has not been studied completely (Ottevanger et al., 2013). With the permanent erosion-accumulative processes in the channel of the Lower Irtysh, one can observe the formation or loss of wintering riverbed depressions of fish, which in turn justifies the need for continuous monitoring of the riverbed depressions. Moreover, the study of movements and spatial distribution of animals provides new information on the distribution of populations of a species in critical habitats, which is useful for its protection among other reasons (Ecclestone et al., 2020; Lin et al., 2020; Moore et al., 2020; Sutton et al., 2021; Withers et al., 2021).

In this regard, the purpose of the work is to establish the presence or absence of fish aggregations by the hydroacoustic method, to determine the bathymetric characteristics of a potential wintering riverbed depression at the confluence of the reforming meanders.

\section{Materials and methods}

The study site is located in the lower reaches of the Irtysh River (ObIrtysh basin) in the Tyumen region (Western Siberia, Russian Federation) at coordinates $58^{\circ} 51 ' 27.7^{\prime \prime} \mathrm{N}, 68^{\circ} 44^{\prime} 31.7^{\prime \prime} \mathrm{E}$ (Fig. 1). Its area is 82.5 ha.

Studies of the distribution of fish were performed using a sonar software and hardware complex AsCor (Promhydroacoustics LLC, Russia). The functioning of this complex is based on the use of a serial dual frequency echo sounder Furuno LS 4100 (Furuno, Japan) with a vertical view. Operating frequencies of the echo sounder are 50 and $200 \mathrm{kHz}$. The hydroacoustic survey was carried out on a grid of traverses (zigzags) from a motorboat (Yudanov et al., 1984). The hydroacoustic survey scheme and the installation of sonar receiver antennas in the cowl on the bow of the motor boat are reflected in Figure 2. The recording was processed in the laboratory using special software applications for determining the density of fish and taxonomic structure. The algorithm of the Taxonomy application for determining the taxonomic structure of the fish population based on the shape of the swim bladder of fish (Borisenko 
et al., 2006) divided them to four groups: (1) cyprinids, (2) percids, (3) pike and coregonids, (4) sturgeons and burbot. The percentage of size groups is calculated as follows: $<5,5-10,10-15,15-20,20-25,25-30$, $30-35$ and $>35 \mathrm{~cm}$.

Two sonar surveys were performed on July 16, 2019, and October 24,2019 . For the convenience of analysis, the water column of the studied section of the river was conditionally divided into two horizons: $<10 \mathrm{~m}-$ surface-pelagic and $>10 \mathrm{~m}-$ pelagic-bottom. The research group carried out control fishing with different-mesh drift fishing nets and fixed fishing nets to determine the species composition of the ichthyofauna.

The tablets (horizontal projection) of fish distribution were created using Surfer 9.0 (Golden Software, USA). To create the tablets, the map was recalibrated in Map Viewer 7.0 (Golden Software, USA) using satellite images of the Earth surface from Google Earth Pro 7.3 (Google, USA).

\section{Results}

As a result of control fishing, it was found that characteristic species of the Lower Irtysh represent its ichthyofauna, with the dominance of cyprinids: roach (Rutilus rutilus Linnaeus, 1758), ide (Leuciscus idus (Linnaeus, 1758)), dace (Leuciscus leuciscus (Linnaeus, 1758)), bream (Abramis brama (Linnaeus, 1758)), crucian carp (Carassius carassius Linnaeus, 1758), silver crucian (Carrassius auratus Linnaeus, 1758). The family of perch fish was represented by three species: perch (Perca fluviatilis Linnaeus, 1758), ruff (Gimnocephalus cernuus Linnaeus, 1758), zander (Sander lucioperca Linnaeus, 1758). Among valuable fish are noted species of Acipenseridae family: sterlet (Acipenser ruthenus Linnaeus, 1758), Siberian sturgeon (Acipenser baerii Brandt, 1869); and the species of Coregonidae family: inconnu (Stenodus leucichthys nelma Pallas, 1773). One species was noted for the Esocidae family: pike (Esox lucius Linnaeus, 1758) and the Lotidae family: burbot (Lota lota Linnaeus, 1758).

As a result of distance echometric sounding of the water column of the studied section of the river and the subsequent creation of horizontal projections of the distribution of fish, it was found that the highest concentration of fish was in the zone of circulating currents formed by the collision of oncoming currents on the transforming meanders (Fig. 3 and 4).

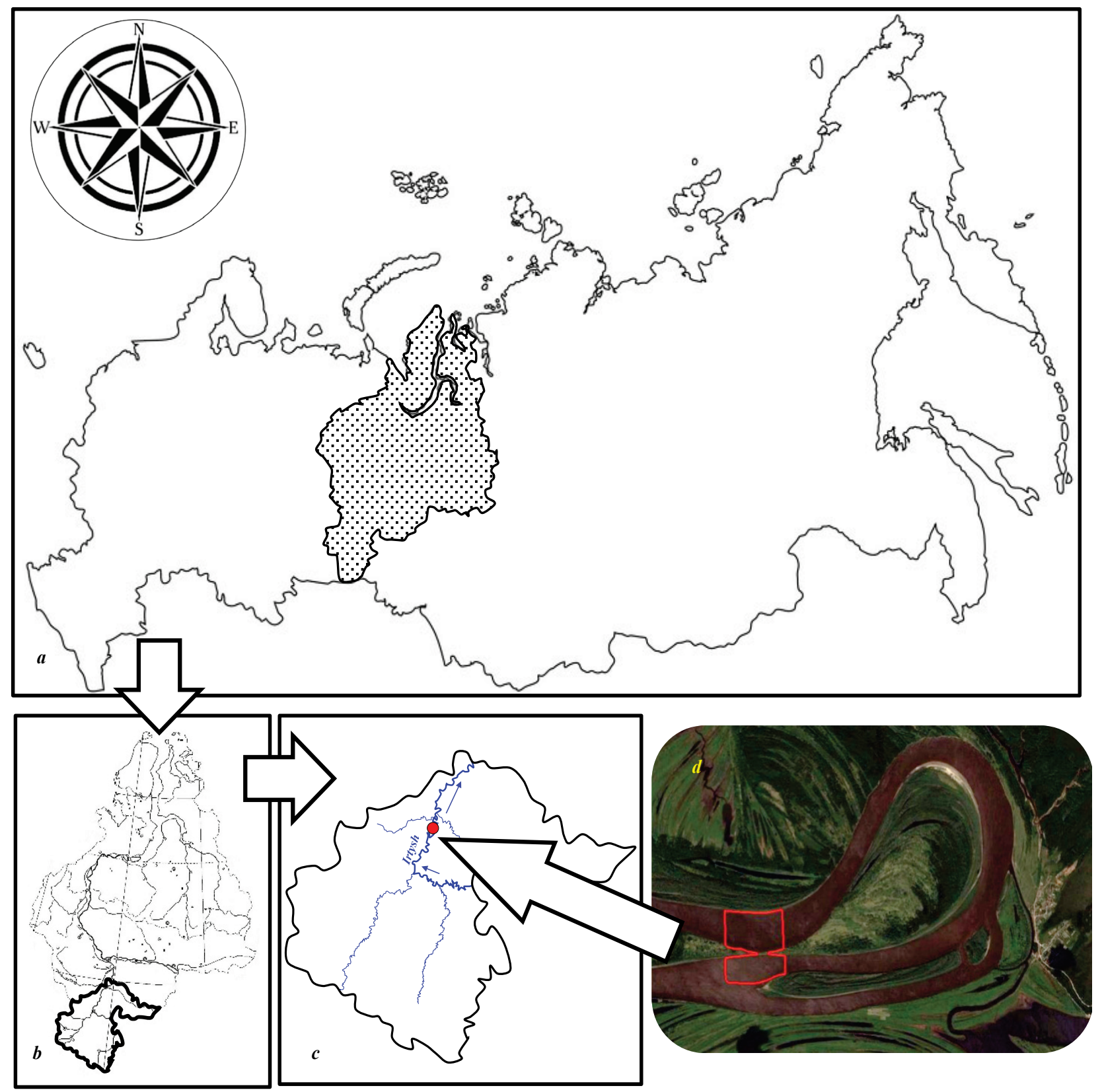

Fig. 1. Schematic map of the location of the studied section of the river: $a$-Russian Federation; $b$-Tyumen region; $c$-location of the study area on the Irtysh River; $d$ - satellite image of the study area 

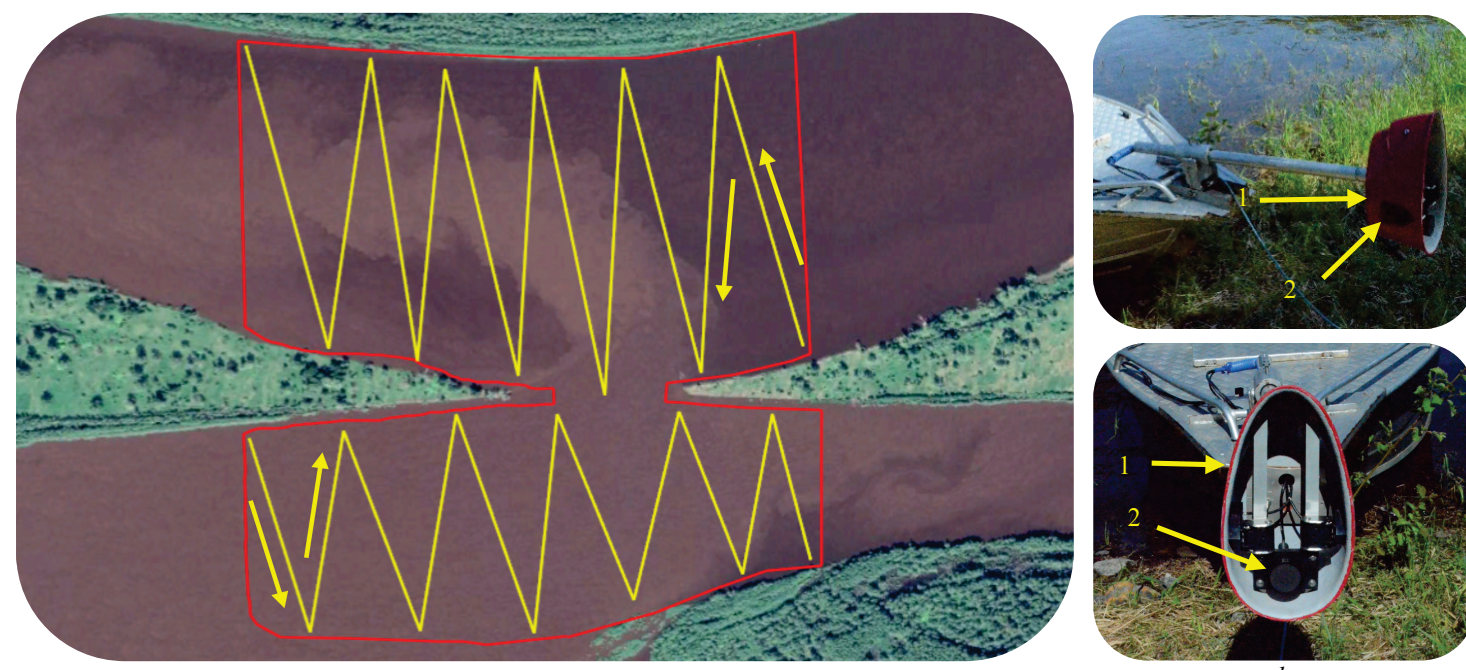

Fig. 2. Research methodology: $a$-the scheme of movement of a motor boat during hydroacoustic survey (yellow arrow line - direction of movement; red line is the border of the study area); $b$-Installation of sonar receiver antennas in the fairing on the bow of the motor boat: 1 - fairing, 2 - receiver antennas

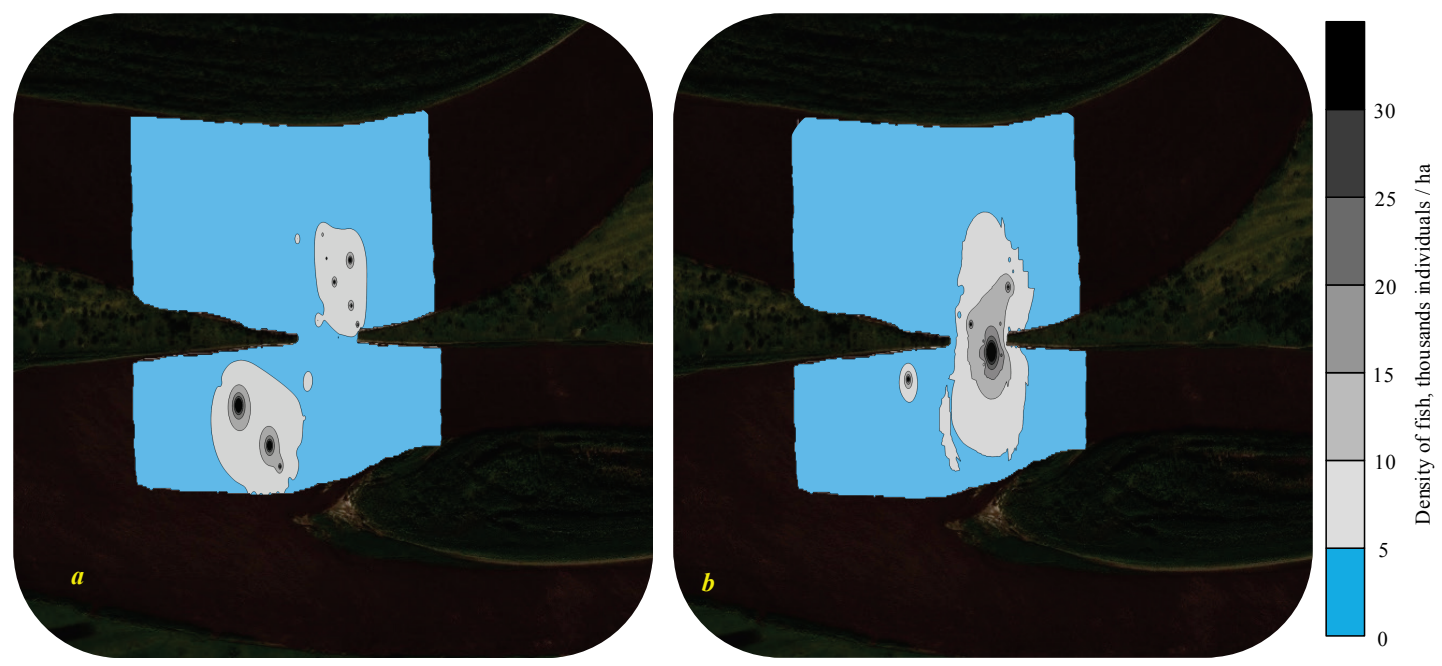

Fig. 3. Tablets (horizontal projections) of the distribution of fish: $a-$ July, $b-$ October

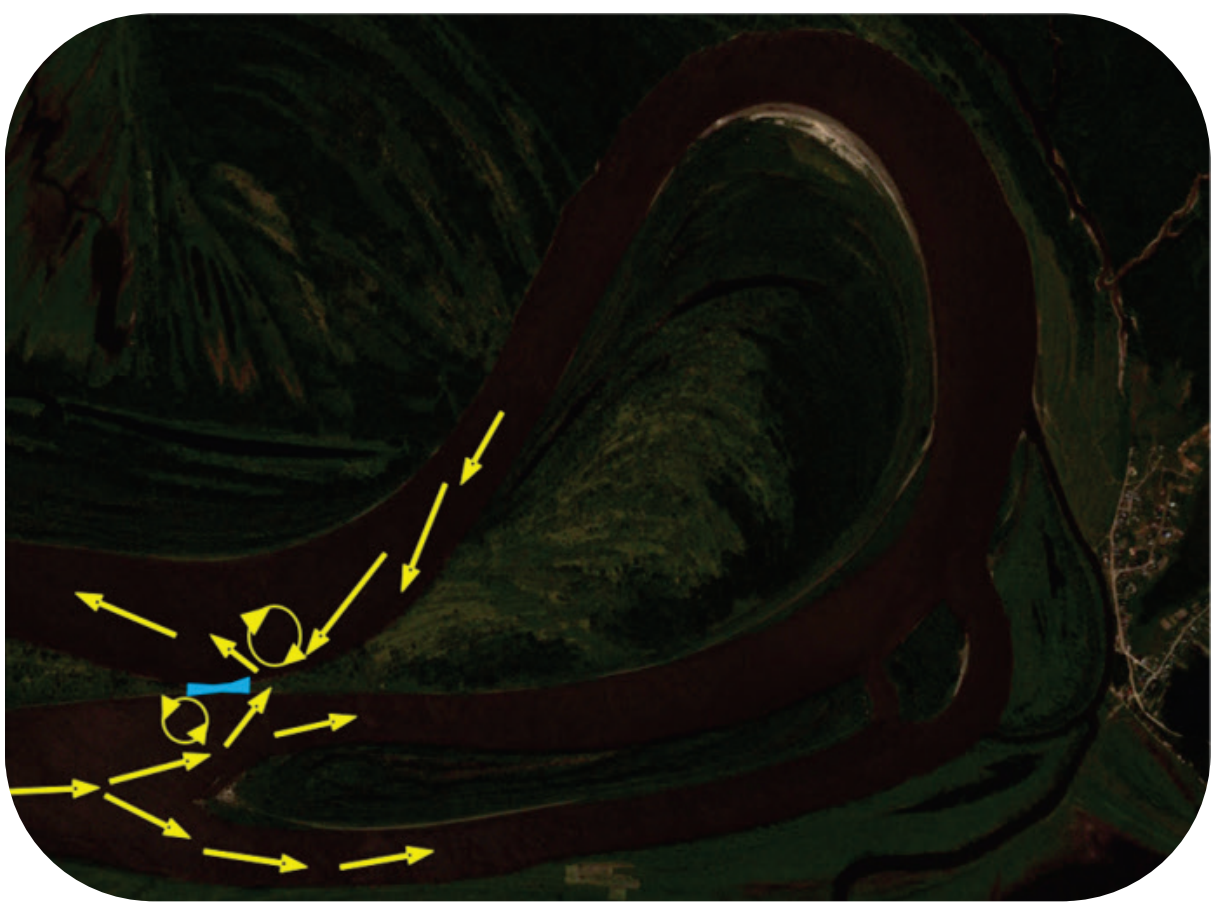

Fig. 4. Scheme of formation of circulating currents and vortices (shown by arrows) in the studied section of the Irtysh 
During the summer survey, the average fish density in the study area was 8,031 fish/ha, in the autumn-9,194 fish/ha; and in the autumn period, the distribution of fish in the horizontal projection had a more aggregated character compared to the summer period. According to the hydroacoustic survey results, cyprinids always dominated: in the summer, their share was $63.7 \%$, in the autumn $-64.0 \%$. The groups of (1) percids, (2) pike and coregonids, (3) burbot and sturgeons were noted (decreasing order). Their shares in the summer and autumn periods of the survey were: $26.1 \%$ and $26.4 \%, 6$ and $5.9 \%, 4.2 \%$ and $3.7 \%$, respectively (Fig. 5).

During the summer and autumn surveys, the depths of the investigated section of the river exceeded 20 and $16 \mathrm{~m}$, respectively. The water level according to the nearest hydrological post Uvat during summer and autumn surveys amounted to 742 and $438 \mathrm{~cm}$, respectively (i.e., water level decreased by $304 \mathrm{~cm}$ ). At the same time, the share of water area with depths of more than $10 \mathrm{~m}$ decreased slightly from $74.7 \%$ in July to $72.3 \%$ in October. It is worth noting that the vertical distribution of fish in summer and autumn was different, while the proportions of water areas with depths $>10 \mathrm{~m}$ of the total area of the studied water area in the summer and autumn were comparable: $42.6 \%$ and $42.1 \%$, respectively (Fig. 5). Cyprinids were unevenly distributed over the horizons of the water column both in summer and autumn: $66.6 \%$ and $84 \%$ in the surface-pelagic horizon, $33.4 \%$ and $16 \%$ in the pelagic-bottom horizon, respectively. A similar pattern was found for percids: from the surface to the bottom in the summer, the proportions of individuals were distributed comparatively: $48.9 \%$ and $51.1 \%$.
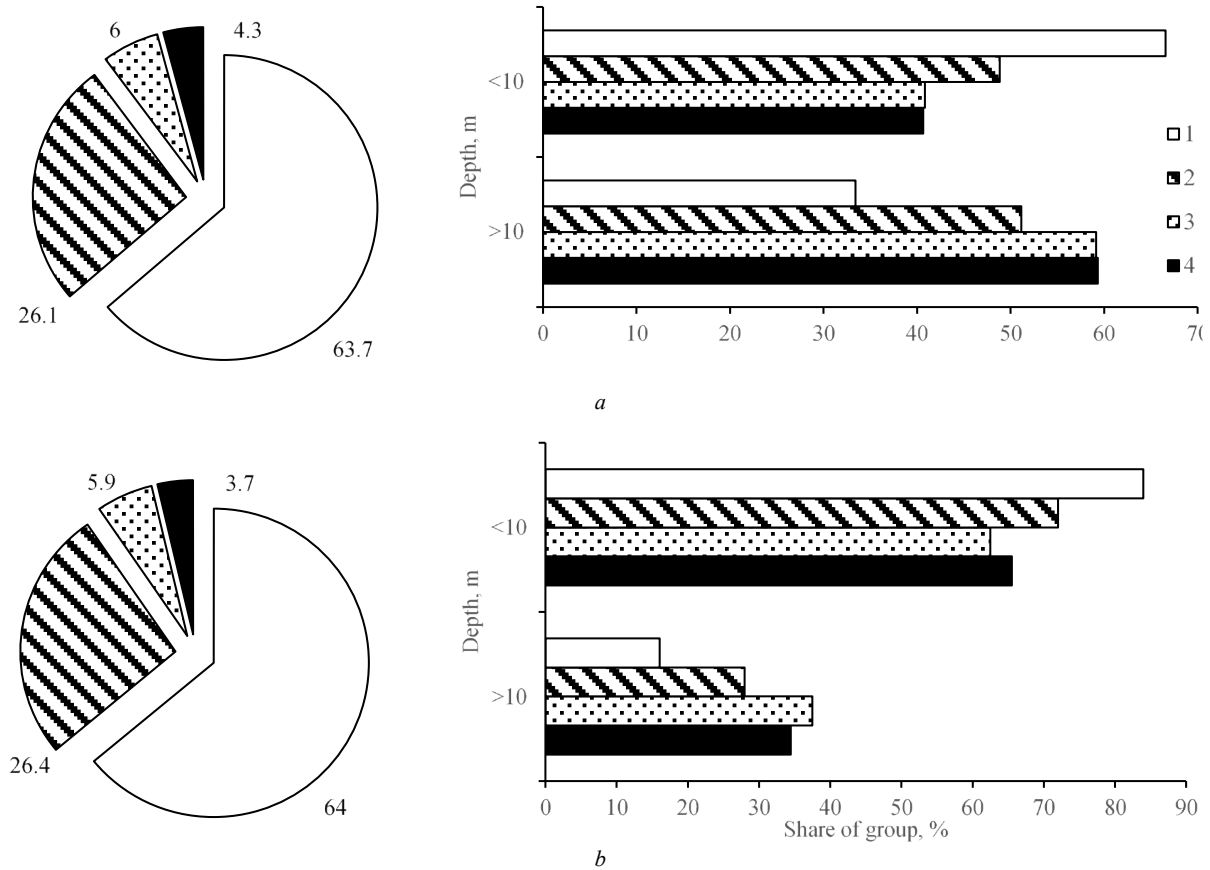

Fig. 5. The proportion of registered groups of fish in the study area of the total number of fish and their vertical distribution over the horizons of the water column: 1 -Cyprinidae, 2 - Percidae, 3 - Coregonidae and Esocidae, 4 - Acipenseridae and Lotidae; $a$ - July; $b$-October

In autumn, percids moved to the surface-pelagic horizon, their share in this horizon was $72 \%$, in the pelagic-bottom $-28 \%$ of the total number of fish in this group. Similarly, there was a vertical distribution of two other fish groups: coregonids and pike, burbot and sturgeons. When viewed from the surface to the bottom in summer, their proportions in the first group were $40.8 \%$ and $59.2 \%$, the second group contained $40.7 \%$ and $59.3 \%$ of the total number of fish of these groups. In the autumn period, the indices of the proportions of the group of coregonids and pike were $62.5 \%$ and $37.5 \%$, in the group of burbot and sturgeons $-65.5 \%$ and $34.5 \%$ of the total number of recorded fish of these groups (Fig. 5).

As a result of the analysis of the ratio of groups of fish with body sizes $<5,5-10,10-15,15-20,20-25,25-30,30-35$ and $>35 \mathrm{~cm}$ among the fish population of the studied section of the river, the differences were noted both along the horizons of water column $(<10$ and $>10 \mathrm{~m})$ and for the seasons (summer, autumn). In summer, the group of cyprinids in the surface-pelagic horizon of the water column $(<10 \mathrm{~m})$ was represented by individuals of all recorded size ranges: $<5,5-10,10-15,15-20,20-25$, $25-30,30-35$ and $>35 \mathrm{~cm}$, their shares were $5.9 \%, 72.0 \%, 16.7 \%, 3.7 \%$, $1.1 \%, 0.4 \%, 0.1 \%$ and $0.1 \%$, respectively, of the total number of cyprinids (Fig. 6a). The group of percids was represented by a smaller number of size groups; there were no fish individuals with body sizes of 20-25, 30 35 , and $>35 \mathrm{~cm}$. Among percids in the surface-pelagic horizon, fish with the body size of $5-10 \mathrm{~cm}$ dominated, their share was $85.8 \%$. The shares of other size groups among percids: $<5,10-15,15-20$ and $25-30 \mathrm{~cm}$ were $7.5 \%, 5.1 \%, 1.3 \%$ and $0.3 \%$, respectively (Fig. 6a).

The group of coregonids and pikes in the examined horizon of the water column in the summer period was represented by all size groups $<5,5-10,10-15,15-20,20-25,25-30,30-35$ and $>35 \mathrm{~cm}$, their shares accounting for $0.4 \%, 31.7 \%, 40.0 \%, 14.2 \%, 6.7 \%, 4.8 \%, 0.7 \%$ and $1.5 \%$, respectively. The group of burbots and sturgeons was represented by all size groups except for large fish with body sizes of $30-35 \mathrm{~cm}$, the share of size groups $<5,5-10,10-15,15-20,20-25,25-30$ and $>35 \mathrm{~cm}$ was $2.8 \%, 50.3 \%, 34.6 \%, 8.6 \%, 1.6 \%, 1.6 \%$ and $0.5 \%$, respectively. Thus, in the summer period, groups of fish with body sizes of 5-10 and 10-15 cm dominated in the surface-pelagic horizon (Fig. 6a).

In the pelagic-bottom horizon of the water column $(>10 \mathrm{~m})$ in summer, cyprinids were also represented by all size groups $-<5,5-10,10-15$, $15-20,20-25,25-30,30-35$ and $>35 \mathrm{~cm}$, their shares equaling $5.3 \%$, $72.4 \%, 17.0 \%, 3.7 \%, 0.9 \%, 0.4 \%, 0.1 \%$ and $0.2 \%$, respectively, of the total number of cyprinids in this water column (Fig. 6b). Among percids, no individuals of the largest sizes with the body length of 30-35 and $>35 \mathrm{~cm}$ were recorded. For other size groups of fish $<5,5-10,10-15,15-$ $20,20-25$ and $25-30 \mathrm{~cm}$, the share accounted for $6.9 \%, 85.3 \%, 5.6 \%$, $1.6 \%, 0.2 \%$ and $0.4 \%$ of the total number of percids in the pelagic-bottom layer of the water column (Fig. 6b). The group of coregonids and pikes was represented by the majority of size groups, except for medium-sized individuals $(25-30 \mathrm{~cm})$. The shares of registered size groups were $<5,5-$ $10,10-15,15-20,20-25,30-35$ and $>35 \mathrm{~cm}$, accounting for $0.9 \%$, $31.8 \%, 44.8 \%, 14.0 \%, 4.8 \%, 0.9 \%$ and $2.8 \%$, respectively, of the total number of coregonids and pikes in this horizon (Fig. 6b). For the group of sturgeons and burbots in the examined horizon of the water column, individuals with the body sizes of $25-30$ and $30-35 \mathrm{~cm}$ were not recorded. For size groups $<5,5-10,10-15,15-20,20-25$ and $>35 \mathrm{~cm}$, the shares were $2.8 \%, 49.9 \%, 36.4 \%, 5.4 \%, 4.1 \%$ and $1.4 \%$, respectively, of the total number of these taxonomic groups at the depths $>10 \mathrm{~m}$ (Fig. 6b).

In the autumn, the vertical distribution and the ratio of size groups changed. In the surface-pelagic horizon of the water column, cyprinids were represented by the majority of size groups; individuals with the body 
size of $30-35 \mathrm{~cm}$ were not recorded. The shares of size groups $<5,5-10$, $10-15,15-20,20-25,25-30$ and $>35 \mathrm{~cm}$ were $8.8 \%, 76.3 \%, 10.3 \%$, $3.3 \%, 0.9 \%, 0.3 \%$ and $0.15 \%$, respectively, of the total number of cyprinids in the examined water column (Fig. 6c). For percids, no individuals of medium and large sizes $25-30,30-35$ and $>35 \mathrm{~cm}$ were seen. For other size groups, $<5,5-10,10-15,15-20$ and $20-25 \mathrm{~cm}$, the shares were $17.9 \%, 73.8 \%, 4.8 \%, 2.4 \%$ and $1.1 \%$, respectively, of the total number of percids in the surface-pelagic horizon of the water column (Fig. 6c). The group of coregonids and pikes was represented by the majority of size groups, except for large individuals with the body size of $30-35 \mathrm{~cm}$. For other size groups $-<5,5-10,10-15,15-20,20-25,25-30$ and $>35 \mathrm{~cm}$ - the shares were $3.0 \%, 44.4 \%, 40.4 \%, 5.0 \%, 3.0 \%, 3.0 \%$, and
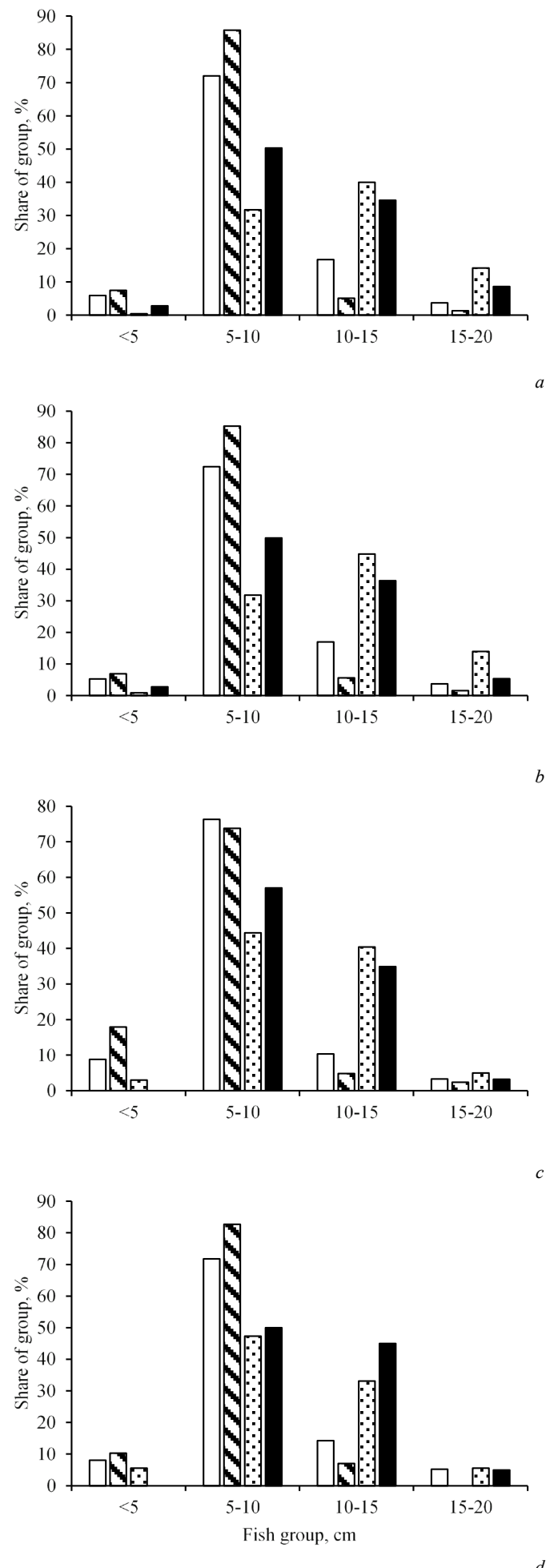

$1.2 \%$, respectively (Fig. 6c). The distribution of the group of sturgeons and burbots in the surface-pelagic horizon was characterized by the absence of individuals with body sizes $<5$ and $>35 \mathrm{~cm}$. For size groups $5-10,10-15$, $15-20,20-25,25-30$ and $30-35 \mathrm{~cm}$, the share indicators were $57.0 \%$, $34.9 \%, 3.2 \%, 3.2 \%, 1.6 \%$ and $0.1 \%$, respectively, of the total number of sturgeons and burbots in the considered water column (Fig. 6c).

In the pelagic-bottom horizon of the water column, cyprinids were represented by size groups $<5,5-10,10-15,15-20$ and $25-30 \mathrm{~cm}$, their shares being $8.1 \%, 71.8 \%, 14.3 \%, 5.2 \%$ and $0.6 \%$, respectively, of the total number of cyprinid at depths $>10 \mathrm{~m}$ (Fig. 6d). Percids were represented by a smaller number of size groups: $<5,5-10$ and $10-15 \mathrm{~cm}$, their shares were $10.3 \%, 82.7 \%$ and $7.0 \%$, respectively (Fig. $6 \mathrm{~d}$ ).
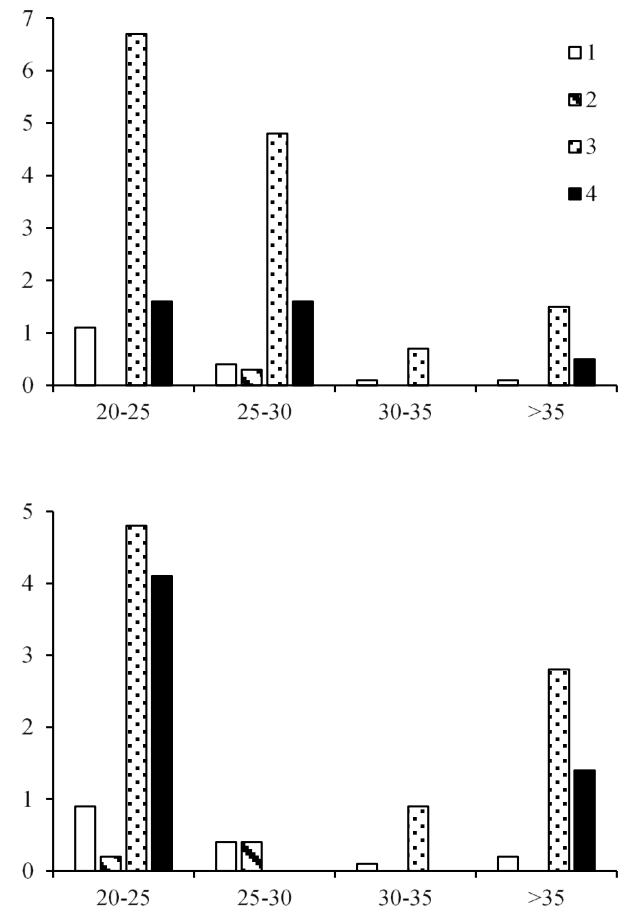

$b$
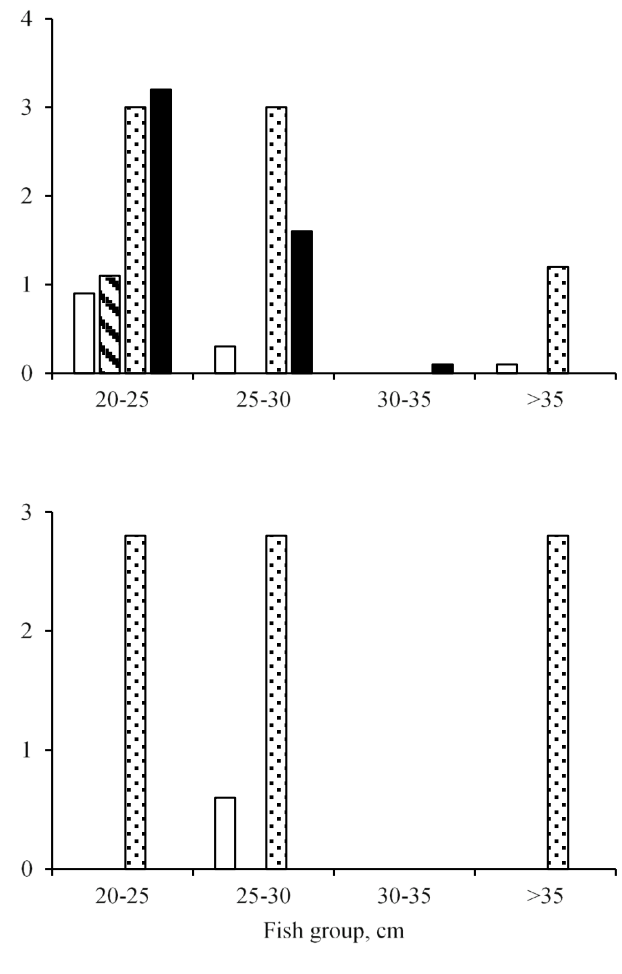

Fig. 6. The share of fish size groups along the horizons of the water column: $a-\mathrm{July},<10 \mathrm{~m} ; b-\mathrm{July},>10 \mathrm{~m} ; c-$ October, $<10 \mathrm{~m} ; d-$ October, $>10 \mathrm{~m}$; 1 -Cyprinidae, 2 - Percidae, 3 - Coregonidae and Esocidae, 4 - Acipenseridae and Lotidae 
The group of coregonids and pikes was represented by the largest number of size groups: $<5,5-10,10-15,15-20,20-25,25-30$ and $>35 \mathrm{~cm}$; no individuals with the body size of $30-35 \mathrm{~cm}$ were observed.

The shares of recorded size groups were $5.6 \%, 47.3 \%, 33.1 \%, 5.6 \%$, $2.8 \%, 2.8 \%$ and $2.8 \%$, respectively, of the total number of this taxonomic group in the pelagic-bottom horizon (Fig. 6d). The group of sturgeons and burbots was characterized by the presence of only three size groups: 5-10, $10-15$ and $15-20 \mathrm{~cm}$, their shares were $50 \%, 45 \%$ and $5 \%$, respectively, of the total number of fish of these families at depths $>10 \mathrm{~m}$ (Fig. 6d).

Thus, in the autumn period, there occurred change in the vertical redistribution of fish in the studied section of the river, with the predominant distribution of fish at depths $<10 \mathrm{~m}$. At the same time, the presence of large individuals was noted in the pelagic-bottom horizon for coregonids and pikes; for other fish, individuals were recorded with body sizes predominantly $<20 \mathrm{~cm}$.

\section{Discussion}

The most actively developing elements of the channel are the vertices of free bends (meander), the displacement rates of which reach from 3-5 to $11 \mathrm{~m}$ per year (Pavleichik et al., 2018). In these areas, complex multidirectional currents are noted (Blanckaert \& de Vriend, 2010; Blanckaert et al., 2013). The concave bank usually erodes (recedes), and shallows form on the convex bank (Blanckaert \& de Vriend, 2010; Blanckaert et al., 2013). In 2019, as a result of the erosive action of the flow in the paired meanders, the Lower Irtysh River demonstrated one of the stages of the loop-shaped (omega-shaped) evolution of the channel (Chalov et al., 2004; Guo et al., 2021; Zhao et al., 2021): the erosion of the isthmus and merging of channel sections with intensive erosion of the river bed (Fig. 3). The study section in the Lower Irtysh should be attributed to the omega-shaped bend, the share of which is $12 \%$ of the total number of bends of various types in the Irtysh River (Chalov et al., 2004). It is also worth noting (Chalov et al., 2004; Alekseevskiy et al., 2008) that the geological and geomorphological structure determines the development of freely meandering channels, while the flat sections of Western Siberia are composed of loose easily eroded rocks (sediments), and the Irtysh River is characterized by meandering.

In winter, many fish species (including sturgeons) show limited movement and form aggregations in "temporary limited biotopes" (Thayer et al., 2017; Mochek et al., 2019; Andrews et al., 2020), which include wintering riverbed depressions of the Lower Irtysh (Mochek et al., 2019).

Wintering sections, for example (Thayer et al., 2017) for lake sturgeon (Acipenser fulvescens Rafinesque, 1817) should be deep and with slow flow. Juveniles were seen to be more prone to the formation of aggregations than fish of older age groups. During the wintering season, the basic habitat requirements of other species of fish also shift to the most important aspects: sufficient depth and low flow rates (Mochek et al., 2019; Wang et al., 2019). In the study of riverbed depressions, it was shown (Mochek et al., 2015) that aggregations of fish in these water areas are also found during open-water periods. The study (Borisenko et al., 2013) revealed that riverbed depressions mostly form on the vertices of meanders. At the same time, vertical vortex structures, zones of increased turbidity, circulation, and counter-currents of flow are founded. Features of a complex heterogeneous environment and the presence of multidirectional flows form turbulence and turbidity in the water column of riverbed depressions (Mochek et al., 2019). These factors can have a protective effect on non-predatory fish (Figueiredo et al., 2016; Ehlman et al., 2019; Ortega et al., 2020).

Features of the change in the vertical distribution of fish, varying equable in summer to predominantly surface-pelagic in autumn, are caused by decreased living space. The water level between sonar surveys decreased by more than $3 \mathrm{~m}$. Having large living spaces and the presence of a certain level of turbulence (Kahl \& Radke, 2006; Pekcan-Hekim et al., 2016; Haak et al., 2018), the level of intraspecies and interspecies competition among fish decreases. It is worth noting that a shift in the distribution of all species of fish (including non-predators and predators) to the surface-pelagic horizon of the water column in the autumn period would not contribute to more active attacks by predators on their prey. It was reported (Westrelin et al., 2017; Roy et al., 2018) that with a decrease in water temperature, the activity and movements of both perch and zander significantly decrease.

\section{Conclusion}

In the studied section of the river (in areas of circulating and countercurrent flows and merging meanders), in the summer-autumn period, the aggregations of fish with the predominance of cyprinids were observed. In the water area of this section around the eroded "isthmus", depths exceeding the $20 \mathrm{~m}$ were found. These features and patterns suggest the fish population uses the newly formed section of the river as a critical "temporarily limited biotope", the wintering riverbed depression, during the winter period of the life cycle.

\section{References}

Akhtari, A. A., \& Seyedashraf, O. (2017). An experimental study of vanes' effects on water depth changes in strongly curved open-channels. Arabian Joumal for Science and Engineering, 42(9), 4015-4022.

Alekseevskiy, N. I., Berkovich, K. M., \& Chalov, R. S. (2008). Erosion, sediment transportation and accumulation in rivers. International Journal of Sediment Research, 23(2), 93-105.

Andrews, S. N., O’Sullivan, A. M., Helminen, J., Arluison, D. F., Samways, K. M., Linnansaari, T., \& Curry, R. A. (2020). Development of active numerating sidescan for a high-density overwintering location for endemic shortnose sturgeon (Acipenser brevirostrum) in the Saint John River, New Brunswick. Diversity, 12(1), 23.

Blanckaert, K., \& de Vriend, H. J. (2010). Meander dynamics: A nonlinear model without curvature restrictions for flow in open-channel bends. Joumal of Geophysical Research, 115(F4), 1301.

Blanckaert, K., Constantinescu, G., Uijttewaal, W., \& Chen, Q. (2013). Hydro- and morphodynamics in curved river reaches - recent results and directions for future research. Advances in Geosciences, 37, 19-25.

Borisenko, E. S., Mochek, A. D., Pavlov, D. S., \& Chemagin, A. A. (2013). Distribution of fish in the river system of the Lower Irtysh. Journal of Ichthyology, 53(1), 16-27.

Borisenko, E. S., Mochek, A. D., Pavlov, D. S., \& Degtev, A. I. (2006). Hydroacoustic characteristics of mass fishes of the Ob-Irtysh basin. Journal of Ichthyology, 46(2), 227-234

Chalov, R. S., Zavadskiy, A. S., \& Panin, A. V. (2004). Rechnyye izluchiny [River bends]. Moscow State University Publishing, Moscow (in Russian).

Chavarrías, V., Schielen, R., Ottevanger, W., \& Blom, A. (2019). Ill posedness in modelling two-dimensional morphodynamic problems: Effects of bed slope and secondary flow. Journal of Fluid Mechanics, 868, 461-500.

Deslauriers, D., Yoon, G. R., Earhart, M. L., Long, C., Klassen, C. N., \& Gary Anderson, W. (2018). Over-wintering physiology of age-0 lake sturgeon (Acipenser fulvescens) and its implications for conservation stocking programs. Environmental Biology of Fishes, 101(4), 623-637.

Ecclestone, A., Haxton, T. J., Pratt, T. C., Wilson, C. C., \& Whillans, T. (2020). Seasonal use of two unregulated Lake Superior tributaries by lake sturgeon. Journal of Great Lakes Research, 46(5), 1369-1381.

Ehlman, S. M., Torresdal, J. D., \& Fraser, D. F. (2019). Altered visual environment affects a tropical freshwater fish assemblage through impacts on predator-prey interactions. Freshwater Biology, 65(2), 316-324.

Fernandes, T., \& McMeans, B. C. (2019). Coping with the cold: Energy storage strategies for surviving winter in freshwater fish. Ecography, 42(12), 2037-2052.

Figueiredo, B. R. S., Mormul, R. P., Chapman, B. B., Lolis, L. A., Fiori, L. F., \& Benedito, E. (2016). Turbidity amplifies the non-lethal effects of predation and affects the foraging success of characid fish shoals. Freshwater Biology, 61, 293-300.

Gerasimov, Y. V., Borisenko, E. S., Bazarov, M. I., \& Stolbunov, I. A. (2019). Density and distribution of fish in a river with a pronounced heterogeneity of the environment: Hydroacoustic survey. Inland Water Biology, 12(S1), 69-75.

Guo, X., Gao, P., \& Li, Z. (2021). Morphological characteristics and changes of two meandering rivers in the Qinghai-Tibet Plateau, China. Geomorphology, 379, 107626.

Haak, C. R., Power, M., Cowles, G. W., \& Danylchuk, A. J. (2018). Hydrodynamic and isotopic niche differentiation between juveniles of two sympatric cryptic bonefishes, Albula vulpes and Albula goreensis. Environmental Biology of Fishes, 102(2), 129-145.

Kahl, U., \& Radke, R. J. (2006). Habitat and food resource use of perch and roach in a deep mesotrophic reservoir: Enough space to avoid competition? Ecology of Freshwater Fish, 15, 48-56.

Lin, P., Chen, L., Gao, X., Wang, C., Gao, X., \& Kang, M. (2020). Spatiotemporal distribution and species composition of fish assemblages in the transitional zone of the three Gorges Reservoir, China. Water, 12(12), 3514. 
Mochek, A. D., Borisenko, E. S., \& Pavlov, D. S. (2019). Winter fish distribution in the riverbed depression in the Irtysh River. Journal of Ichthyology, 59(3), 352-357.

Mochek, A. D., Borisenko, E. S., Pavlov, D. S., Chemagin, A. A., \& Budaev, S. V. (2015). Factors affecting the distribution of fish during receding flood in lower Irtysh: Effects of water level and diurnal cycle. Annales de Limnologie, 51(2), 89-100.

Moore, M. J., Paukert, C. P., \& Moore, T. L. (2020). Effects of latitude, season, and temperature on lake sturgeon movement. North American Journal of Fisheries Management, 41(4), 916-928.

Ortega, J. C. G., Figueiredo, B. R. S., Graça, W. J., Agostinho, A. A., \& Bini, L. M. (2020). Negative effect of turbidity on prey capture for both visual and non-visual aquatic predators. Journal of Animal Ecology, 89(11), 2427-2439.

Ottevanger, W., Blanckaert, K. J. Uijttewaal, W. S., \& de Vriend, H. J. (2013). Meander dynamics: A reduced-order nonlinear model without curvature restrictions for flow and bed morphology. Journal of Geophysical Research: Earth Surface, 118(2), 1118-1131.

Pavleichik, V. M., Sivokhip, Z. T., \& Padalko, Y. A. (2018). Dinamika ruslovykh protsessov v srednem techenii reki Ural i riski prirodopolzovaniya [Dynamics of riverbed evolution in the middle Ural River and natural management risks]. Izvestiya Rossiiskoi Akademii Nauk, Seriya Geograficheskaya, 5, 37-45 (in Russian).

Pavlov, D. S., \& Mochek, A. D. (Eds.). (2006). Ekologiya ryb Ob-Irtyshskogo basseyna [Ecology of fish of the Ob-Irtysh basin]. Partnership of Scientific Publishing, Moscow (in Russian).

Pavlov, D. S., Mochek, A. D., Borisenko, E. S., Degtev, E. A., \& Degtev, A. I. (2010). Irregularities of the bottom and fish aggregations on a stretch of the Irtysh. Journal of Ichthyology, 50(11), 997-1001.

Pavlov, D. S., Mochek, A. D., Borisenko, E. S., Degtev, E. A., \& Degtev, A. I. (2011). Skopleniya ryb v ruslovoy kotlovine Irtysha [Aggregations of fish in the riverbeds depression of the Irtysh River]. Rybnoe Khozyaystvo, 2, 86-89 (in Russian).

Pekcan-Hekim, Z., Hellén, N., Härkönen, L., Nilsson, P. A., Nurminen, L., \& Horppila, J. (2016). Bridge under troubled water: Turbulence and niche partitioning in fish foraging. Ecology and Evolution, 6, 8919-8930.

Roy, R., Tissot, L., \& Argillier, C. (2018). Environmental drivers of fish spatial distribution and activity in a reservoir with water level fluctuations. Hydroécologie Appliquée, 21, 25- 46.
Secor, S. M., \& Carey, H. V. (2016). Integrative physiology of fasting. Comprehensive Physiology, 6, 773-825.

Studd, E. K., Bates, A. E., Bramburger, A. J., Fernandes, T., Hayden, B., Henry, H. A. L., Humphries, M. M., Martin, R., McMeans, B. C., Moise, E. R. D., O’Sullivan, A. M., Sharma, S., Sinclair, B. J., Sutton, A. O., Templer, P. H., Cooke, S. J. (2021). Nine maxims for the ecology of cold-climate winters. BioScience, 71(8), 820-830.

Sutton, A. O., Studd, E. K., Fernandes, T., Bates, A. E., Bramburger, A. J., Cooke, S. J., Hayden, B., Henry, H. A. L., Humphries, M. M., Martin, R., McMeans, B., Moise, E., O’Sullivan, A. M., Sharma, S., \& Templer, P. H. (2021). Frozen out: Unanswered questions about winter biology. Environmental Reviews, 29, 431-442.

Takegaki, T., \& Takeshita, F. (2020). Winter mortality of young mudskipper fish: Effects of size, temperature and energy depletion. Journal of Experimental Marine Biology and Ecology, 530-531, 151436.

Tang, X., \& Knight, D. W. (2015). The lateral distribution of depth-averaged velocity in a channel flow bend. Journal of Hydro-Environment Research, 9(4), 532-541.

Thayer, D., Ruppert, J. L. W., Watkinson, D., Clayton, T., \& Poesch, M. S. (2017). Identifying temporal bottlenecks for the conservation of large-bodied fishes: Lake sturgeon (Acipenser fulvescens) show highly restricted movement and habitat use over-winter. Global Ecology and Conservation, 10, 194-205.

Wang, L., Mo, K., Chen, Q., Zhang, J., Xia, J., \& Lin, Y. (2019). Estimating ecological flows for fish overwintering in plain rivers using a method based on water temperature and critical water depth. Ecohydrology, 12(5), e2098.

Westrelin, S., Roy, R., Tissot-Rey, L., Bergès, L., \& Argillier, C. (2017). Habitat use and preference of adult perch (Perca fluviatilis L.) in a deep reservoir: Variations with seasons, water levels and individuals. Hydrobiologia, 809(1), 121-139.

Withers, J. L., Takade-Heumacher, H., Davis, L., Neuenhoff, R., Albeke, S. E., \& Sweka, J. A. (2021). Large- and small-scale movement and distribution of acoustically tagged lake sturgeon (Acipenser fulvescens) in eastern Lake Erie. Animal Biotelemetry, 9(1), 40.

Yudanov, K. I., Kalikhman, I. L., \& Tesler, V. D. (1984). Rukovodstvo po provedeniyu gidroakusticheskikh syemok [Guidelines for hydroacoustic surveys]. Russian Federal Research Institute of Fisheries and Oceanography Publishing, Moscow (in Russian).

Zhao, K., Lanzoni, S., Gong, Z., \& Coco, G. (2021). A numerical model of bank collapse and river meandering. Geophysical Research Letters, 48(12), e2021GL093516. 